\title{
Regeneration of geothermal-sludge based sodium silicate catalyst for transesterification of palm oil with methanol
}

\author{
I. Perdana*, Lenny, I. M. Bendiyasa \\ Department of Chemical Engineering, Universitas Gadjah Mada \\ Jl. Grafika 2, Bulaksumur, 55281 Yogyakarta, Indonesia \\ *Email: iperdana@ugm.ac.id
}

\begin{abstract}
Sodium silicate synthesized from geothermal sludge of a geothermal power plant in Indonesia was applied as a solid catalyst to catalyze transesterification reaction of palm oil with methanol. In our previous study, it has been found that the catalyst deactivated due to hydrocarbon contamination on its surface. In the present work, 3 (three) different regeneration methods were studied for reactivation of the catalyst. The studied methods were: 1) calcination at $400^{\circ} \mathrm{C}$ for 3 hours with a ramp of $20^{\circ} \mathrm{C} /$ minutes, 2) $1 \mathrm{x}$-washing with methanol at room temperature, and 3) $3 \mathrm{x}$-washing with methanol at $60^{\circ} \mathrm{C}$. The performance of the catalyst was studied by sequential reaction batches to monitor the reaction yield from time to time. The sequence consisted of 4 (four) transesterification reaction cycles, with a catalyst regeneration process before reused in subsequence cycle. Experimental results showed that although none of the regeneration processes regained catalyst activity as high as that of the freshly-activated catalyst, the third regeneration method, i.e. $3 \mathrm{x}$-washing with methanol at $60^{\circ} \mathrm{C}$ regained higher catalyst activity compared to the other two studied methods. The method could maintain the reaction conversion at about $50 \%$ after four cycles of reaction and regeneration, Furthermore, the kinetics of the catalytic transesterification reaction was studied by fitting the experimental data with calculated yield obtained from mathematical modelling. It was found that among the first, second, and third order reaction kinetics, the experimental data was best fitted by the calculated results from the first order reaction kinetics. Results from this work suggested that even though $3 \mathrm{x}$-washing regeneration of sodium silicate catalyst with methanol at $60^{\circ} \mathrm{C}$ offered relatively high reactivation, further study for improvement is still needed.
\end{abstract}

Keywords: Geothermal sludge; sodium silicate; transesterification; deactivation; regeneration.

\section{INTRODUCTION}

In the last few years, many efforts have been done to find potential materials that provide renewable energy as the substitute for fossil fuel [1-4]. Biodiesel is among the potential materials that attracts the interest of many researchers due to the abundant availability of its raw materials such as vegetable oil, animal fat, and algae [2-6]. Most of biodiesel synthesis requires the use of catalyst to obtain high yield. In the case of transesterification synthesis route, homogeneous base catalysts prepared from alkali and earth alkaline groups are generally utilized. This type of reaction offers a high yield, however, complicated and cost-demanding separation and purification of products. In this context, 
heterogeneous base catalyst is a better alternative, in which solid alkali or earth alkaline based catalysts such as $\mathrm{CaO}$ [7-9], $\mathrm{Ca}\left(\mathrm{OCH}_{3}\right)_{2}$ [10], and $\mathrm{Na}_{2} \mathrm{SiO}_{3}[11,12]$ can be used in the transesterification reaction. In particular, sodium silicate $\left(\mathrm{Na}_{2} \mathrm{SiO}_{3}\right)$ is solid base catalyst that is suitable for biodiesel production through transesterification reaction because it can avoid soap formation and it can be easily separated from the reaction mixture $[11,13]$.

The synthesis of sodium silicate from different silica $\left(\mathrm{SiO}_{2}\right)$ sources such as clay [14] and coal fly ash [15] has been reported in literature. Another highly potential source is geothermal sludge that contains a high amount of silica [16-19]. The existence of numerous volcanoes in Indonesia has made the country rich in geothermal sources for the production of electrical power. One of operating geothermal power plants in Indonesia is PT. Geo Dipa Energi at Dieng, which produces $60 \mathrm{MW}$ electricity. Despite the high potency of geothermal resource to generate electricity, it is frequently found that the geothermal fluid brings up a high amount of silica-containing brine from the earth that can precipitate and causes massive scaling problems in the pipelines [16-19]. Controlled precipitation, extraction, and utilization of silica from geothermal sludge is therefore an attractive solution in order to eliminate and, at the same time, increase the value of "wastes" resulted from the geothermal power plant. The synthesis of sodium silicate catalyst from silica extracted from geothermal sludge has been previously reported [13]. The resulting sodium silicate was then used as a solid base catalyst for transesterification reaction between triglycerides from palm oil and methanol. The catalyst was however found to deactivate during reactions. Similar deactivation of heterogeneous catalyst was also reported [20-22].

There are several causes of deactivation such as sintering or aging that changes the structure of the catalyst, coking or fouling due to deposition of coke on catalyst surface, and poisoning due to the irreversible chemisorption of impurities. The deactivation of sodium silicate catalysts has been studied by Guo and co-workers [11] using commercial sodium silicate as well as found in our previous studies using sodium silicate from silica gel [23] and geothermal sludge. To the best of our knowledge, there have been no reports so far regarding regeneration of sodium silicate catalysts, in particular those prepared from geothermal sludge.

The present work thus presents a systematic study on the regeneration of geothermal sludge-based sodium silicate catalyst that leads to reactivation of the catalyst for the transesterification reaction between palm oil and methanol. It has been reported that calcining deactivated catalysts may burn out the deposited carbon on the catalyst surface leading to its reactivation [24-26]. Many authors have also reported successful reactivation of different heterogeneous catalysts using mechanical and/or chemical washing methods [27-31]. The present work reported 3 (three) different regeneration methods, i.e. calcination at $400^{\circ} \mathrm{C}$, washing treatment at room temperature, and washing treatment at $60^{\circ} \mathrm{C}$. By monitoring the reaction yield from time to time at different reaction cycles, the most suitable regeneration treatment could be determined. Furthermore, the kinetics of transesterification reaction using the catalyst that had been regenerated with the most suitable method was evaluated. 


\section{METHODS AND MATERIALS}

\section{Materials}

Materials used in this work were geothermal sludge from geothermal power plant PT Geo Dipa Energy at Dieng, Indonesia, sodium hydroxide $(\mathrm{NaOH})$ (Merck, 99.9\%, pro analytic), methanol (Merck, 98\%, pro analytic) and palm oil (Tropical).

\section{Transesterification reaction}

Preparation of sodium silicate catalyst and transesterification procedure were performed following previously reported works [13]. The sodium silicate was prepared from $\mathrm{NaOH}$ and silica extracted from geothermal sludge using gelation method. The catalyst was then activated by calcination at the temperature of $400^{\circ} \mathrm{C}$ for 3 hours with a temperature increase of $20^{\circ} \mathrm{C} /$ minute.

In the transesterification reaction, palm oil (200 g) was added into a beaker glass and heated to $60^{\circ} \mathrm{C}$. Meanwhile, sodium silicate catalyst $(6 \mathrm{~g})$ was added into methanol $(260 \mathrm{ml})$ in a three-necked flask equipped with reflux condenser, mercury stirrer and thermometer. The mixture was heated to $60^{\circ} \mathrm{C}$ and then stirred for $60 \mathrm{~min}$ to activate the methanol adsorbed on catalyst. After $60 \mathrm{~min}$ of stirring, palm oil at $60^{\circ} \mathrm{C}$ was added into the methanol-sodium silicate mixture, and reaction time was counted as $t=0$. Three flasks with similar mixture were prepared to fulfill the necessity of variation of catalyst regeneration methods studied in this work. The transesterification was conducted for 60 min with a stirring speed of $410 \mathrm{rpm}$, while the temperature was maintained steady at $60^{\circ} \mathrm{C}$. From each reaction flask, $5 \mathrm{ml}$ sample was taken at $\mathrm{t}=5,7,10,15,20,25,40$ and $60 \mathrm{~min}$, added into a test tube, and the $\mathrm{pH}$ was measured. Each sample was then centrifuged for 5-10 minutes with a speed of $200 \mathrm{rpm}$ and left until 2 (two) liquid phases was formed. The heavier phase $(1 \mathrm{~g})$ was then taken for glycerol analysis using standard iodometry method. For all transesterification reactions during the entire study, the mass ratio between methanol/palm oil/catalyst was kept constant. The reaction was repeated for 4 (four) cycles, with a catalyst regeneration in between two consecutive cycles.

\section{Regeneration of catalyst}

There were 3 (three) methods of catalyst regeneration studied in this work, i.e. calcination, one-time $(1 \mathrm{x})$ washing at room temperature, and three-times $(3 \mathrm{x})$ washing at $60^{\circ} \mathrm{C}$. The transesterification reaction and catalyst regeneration processes were performed in a sequential process. The first step was synthesis and activation of sodium silicate catalyst that resulted in freshly-activated catalyst. The catalyst was then used in transesterification reaction cycle 1 . The next step was regeneration of the catalyst using one of the three above-mentioned methods followed by transesterification reaction cycle 2 . This cycle was continued by regeneration of the catalyst using the same method. The process was repeated until transesterification reaction cycle 4.

\section{Calcination}

The remaining reaction mixture inside the flask was transferred into a porcelain cup. Due to density difference, the mixture spontaneously created three layers, i.e. methanol in the upper, oil in the middle, and catalyst at the bottom phase. The methanol and oil were taken carefully using drop pipette, leaving the catalyst at the bottom of the porcelain cup. The catalyst was calcined in a furnace at $400^{\circ} \mathrm{C}$ for 3 hours with a temperature ramp of $20^{\circ} \mathrm{C} /$ minute. The catalyst was then weighed using digital analytical scale, and was reused for the next transesterification reaction cycle. 


\section{One time (1x)-washing at room temperature}

The remaining reaction mixture inside the flask was transferred into a centrifuge tube and centrifuged for 10 minutes with a rotation speed of $200 \mathrm{rpm}$. The precipitated catalyst was then separated from the oil and methanol layers. Fresh methanol $(260 \mathrm{ml})$ was added to and mixed with the catalyst. The mixture of methanol and catalyst was added into palm oil in a three-necked flask for the next transesterification reaction.

\section{Three time (3x)-washing at $60^{\circ} \mathrm{C}$}

The remaining reaction mixture inside the flask was transferred into a beaker glass and was allowed for natural separation of methanol, oil, and the catalyst. The oil and methanol layers was then carefully taken from the beaker using drop pipette. The remaining catalyst with a minimum amount of remaining methanol and oil was then mixed with fresh methanol $(50 \mathrm{ml})$. The mixture was heated up and continuously stirred with a magnetic stirrer at $60^{\circ} \mathrm{C}$ for $10 \mathrm{~min}$. Afterwards, the mixture was again allowed for natural separation. Repeating the first washing step, the methanol was pipetted out, leaving the catalyst at the bottom of the beaker. The third washing step was done following identical procedure as the first two. After the third washing step, the catalyst was heated in an oven at $80^{\circ} \mathrm{C}$ for 30 minutes, cooled down at room temperature, weighed, and reused for the next transesterification reaction cycle.

\section{The kinetics study of catalytic transesterification reaction}

The kinetics of transesterification reaction (Equation 1), assuming the system is pseudohomogeneous, was studied using simplified model of first, second and third order reactions with respect to triglyceride concentration [32, 33].

$$
\text { Triglycerides }+ \text { Methanol } \rightarrow \text { Methylesters + Glycerol }
$$

A mass balance developed on triglyceride in a batch reactor results in a correlation between yield $(x)$ and time $(t)$ for each order of reaction as follows:

$$
\begin{array}{ll}
\text { First order } & :-\ln \ln (1-x)=k_{1} \cdot t \\
\text { Second order } & : \frac{x}{1-x}=k_{2} \cdot C_{A 0} \cdot t \\
\text { Third order } & : \frac{1}{2(1-x)^{2}}-\frac{1}{2}=k_{3} \cdot C_{A 0} \cdot t
\end{array}
$$

For further simplification, the form of linear correlations in equation (2), (3) and (4) can be written as follows:

where:

$$
p=A q+B
$$

$k_{1}, k_{2}, k_{3}$ : apparent reaction rate constant of first, second, and third order reaction, respectively.

$C_{A 0}$ : initial concentration of triglycerides.

In this study, calculated results were compared with experimental data to obtain the most appropriate kinetics model. Only transesterification reaction using the catalyst that had been regenerated with the most suitable method was evaluated. 


\section{RESULTS AND DISCUSSION}

As described previously, three different regeneration methods of sodium silicate catalyst were investigated in the present work i.e. regeneration with calcination, $1 \mathrm{x}$-washing and $3 \mathrm{x}$-washing at $60^{\circ} \mathrm{C}$. The reaction yield as a function of time at each cycle in the transesterification of palm oil using calcination-regenerated catalyst is shown in Figure 1.

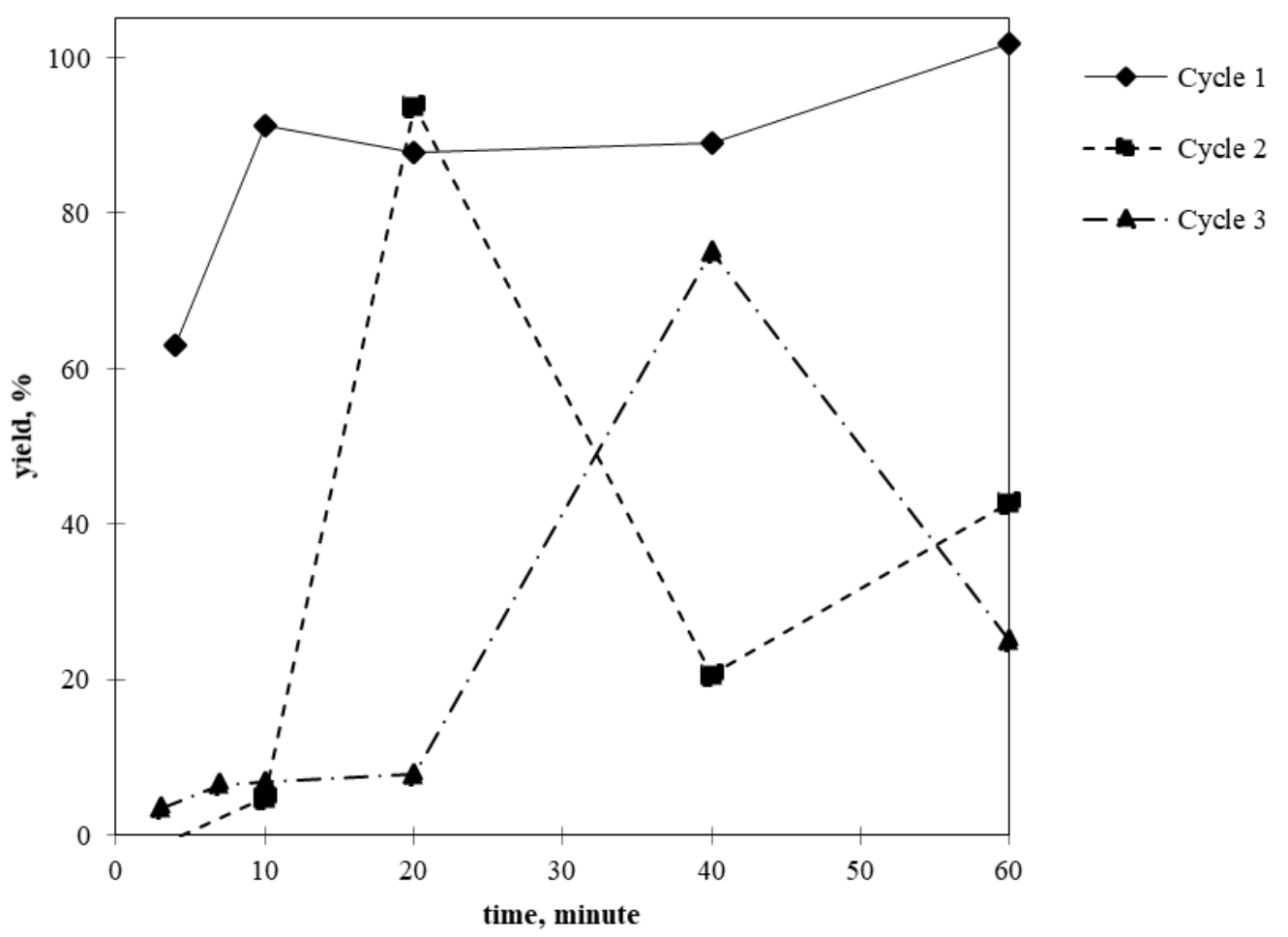

Figure 1. Reaction yield as a function of time in the transesterification of palm oil using freshly-activated catalyst (cycle 1) and calcination-regenerated catalyst (cycle 2 and 3).

It is seen in Figure 1 that the yield increases as a function of reaction time at cycle 1, with the most significant increase observed in the first ten minutes of reaction. This phenomenon indicates that the reaction can occur considerably fast with the use of freshly-activated catalyst. A complete (100\%) conversion of palm oil can be achieved in the given experimental reaction time in this study $(60 \mathrm{~min})$. Following the completion of the reaction, the catalyst was separated, underwent calcination regeneration process, and was reused for the next cycle.

Figure 1 shows a significant decrease in reaction yield at both cycles 2 and 3 compared to that at cycle 1 , although the yield at cycle 2 is relatively higher compared to that at cycle 3. Gui et al. [34] also reported similar results that the activity of catalyst without further purification and activation dropped significantly at the third cycle. This observed phenomena strongly show that the catalyst experiences deactivation, despite the calcination step using a regeneration method. In addition, the catalyst after calcination was visually darker compared to that before calcination. This visual appearance indicates that the catalyst was poisoned by either glycerol or glycerides in palm oil. The presence of these hydrocarbon compounds adsorbed on the catalyst might then lead to the formation of unburned carbon on the catalyst during calcination. The catalyst experienced 
a more severe poisoning at cycle 4 (data not shown), in which the catalyst became completely inactive and visually black. In addition, deactivation of sodium silicate catalyst can also be due to sodium leached by reaction mixture [32]

The reaction yield as a function of time at each cycle in the transesterification of palm oil using $1 \mathrm{x}$-washing (with methanol at room temperature)-regenerated catalyst is shown in Figure 2. It is seen that the yield increases with time, but decreases with the cycle number. The $1 \mathrm{x}$-washing regeneration method, however, can slightly increase the yield in comparison to the calcination regeneration method. In this case, the methanol can partly remove hydrocarbon compounds that remain on the catalyst surface from the previous cycle, leading to more available active sites on the catalyst surface for the reaction. However, it seems that the attachment of the hydrocarbons on the surface is relatively strong, so that $1 \mathrm{x}$-washing at room temperature is not sufficient to remove a big fraction of the hydrocarbons. In the next experimental section, both the number of washing steps and the temperature were increased.

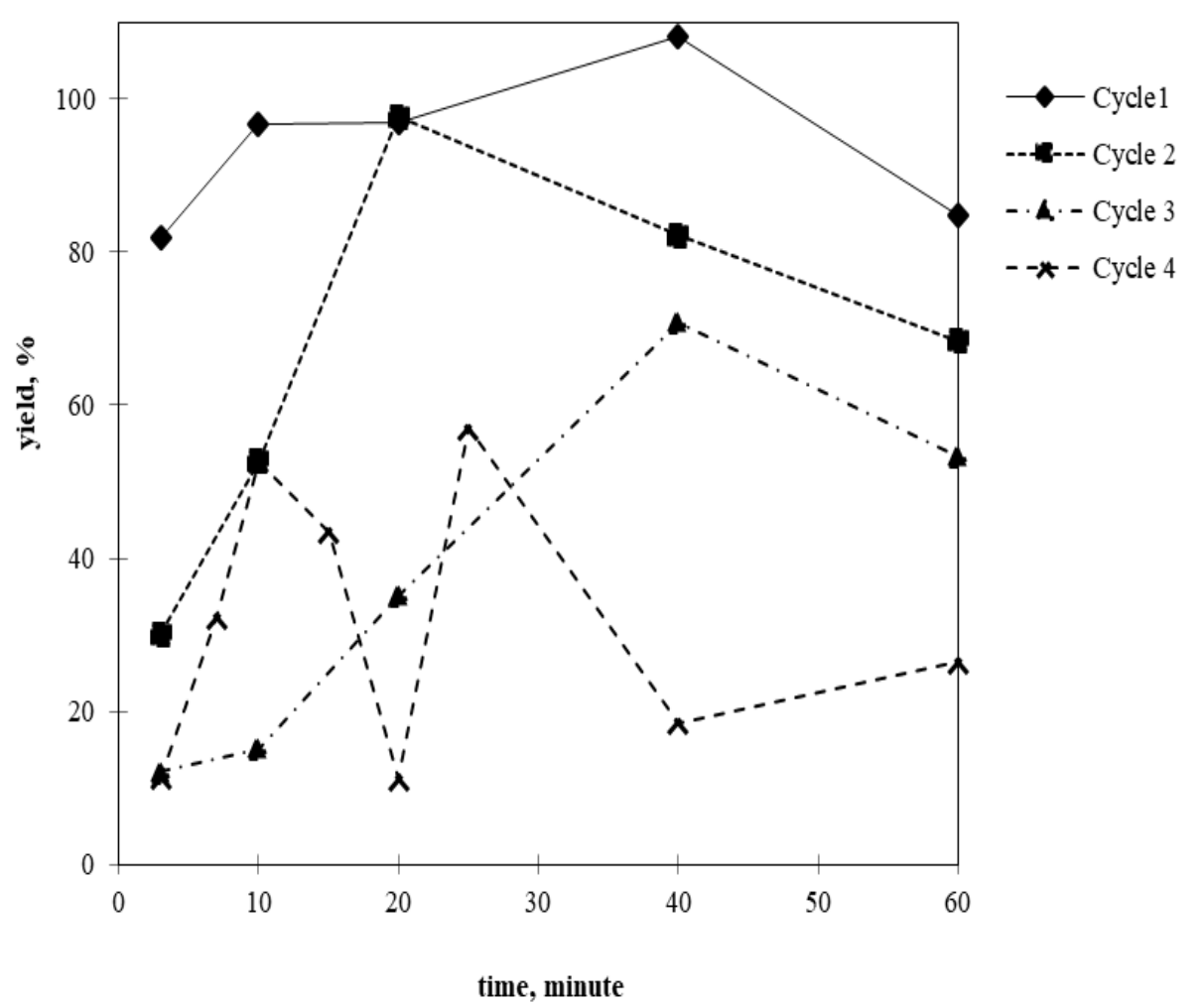

Figure 2. Reaction yield as a function of time in the transesterification of palm oil using freshly-activated catalyst (cycle 1) and 1x-washing (with methanol at room temperature)regenerated catalyst (cycle 2,3 , and 4 ).

The reaction yield as a function of time at each cycle in the transesterification of palm oil using $3 \mathrm{x}$-washing (with methanol at $60^{\circ} \mathrm{C}$ )-regenerated catalyst is shown in Figure 3. In comparison with the other previous regeneration methods, at identical reaction cycle number, the reaction yield tends to improve significantly. At the fourth reaction cycle, about $50 \%$ reaction yield after 60 min was still achievable. This observed phenomenon suggests that a larger fraction of adsorbed hydrocarbon compounds that remain on the catalyst surface after reaction can be removed at high temperature in methanol, leading to even more active surfaces for the transesterification reaction in the next cycle. 


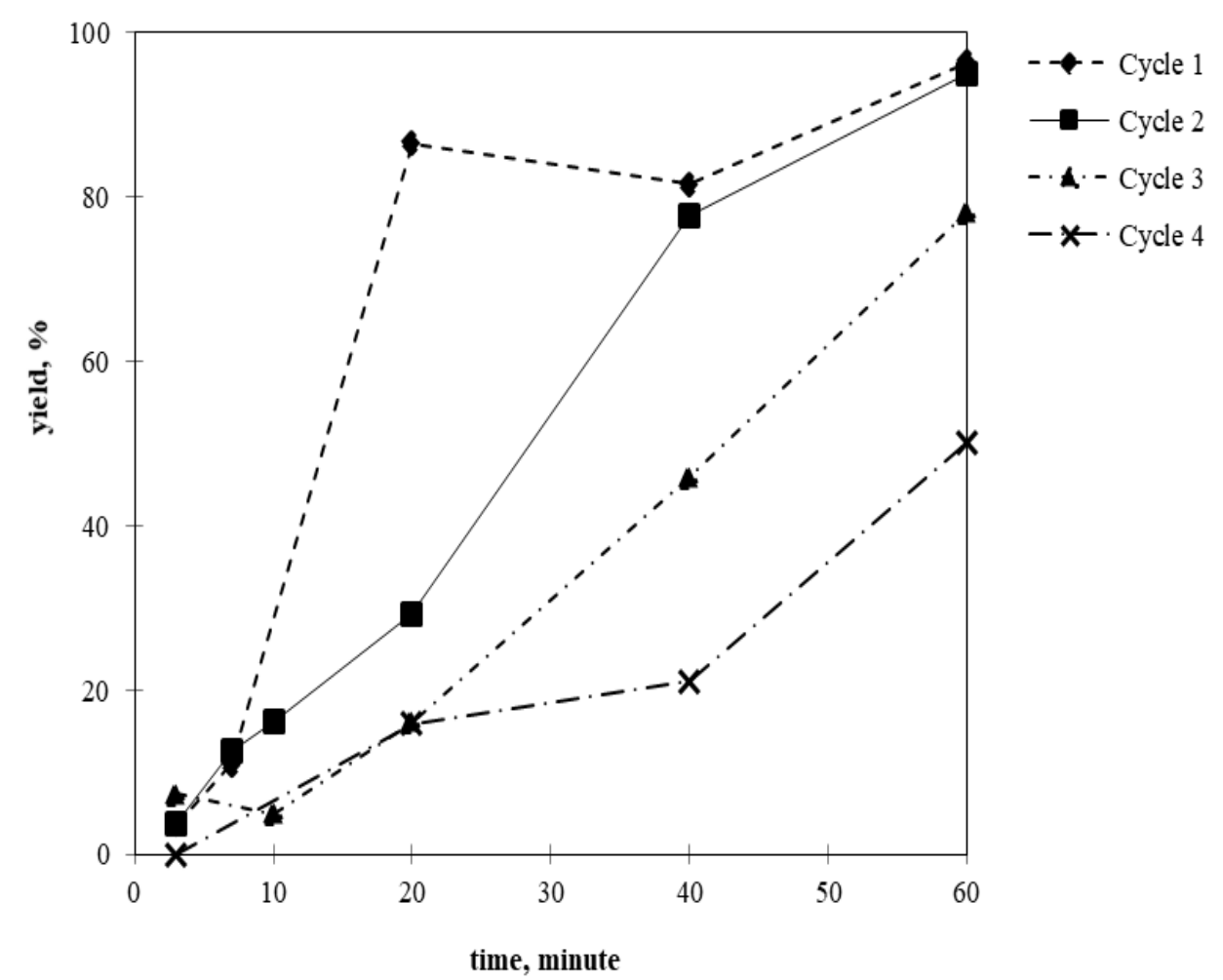

Figure 3. Reaction yield as a function of time in the transesterification of palm oil using freshly-prepared catalyst (cycle 1) and 3x-washing (with methanol at $60^{\circ} \mathrm{C}$ )-regenerated catalyst (cycle 2, 3, and 4).

As described above, among three regeneration methods studied in this work, regeneration with $3 \mathrm{x}$-washing at $60^{\circ} \mathrm{C}$ offers the largest recovery from catalyst deactivation. However, it is observed that the catalyst still experiences deactivation phenomena to some extent, indicative from a systematic decrease of reaction yield as number of reaction cycle increases (Figure 4). It is therefore important to quantitatively determine the activity of the regenerated catalyst in correspond to the number of reaction cycles. 


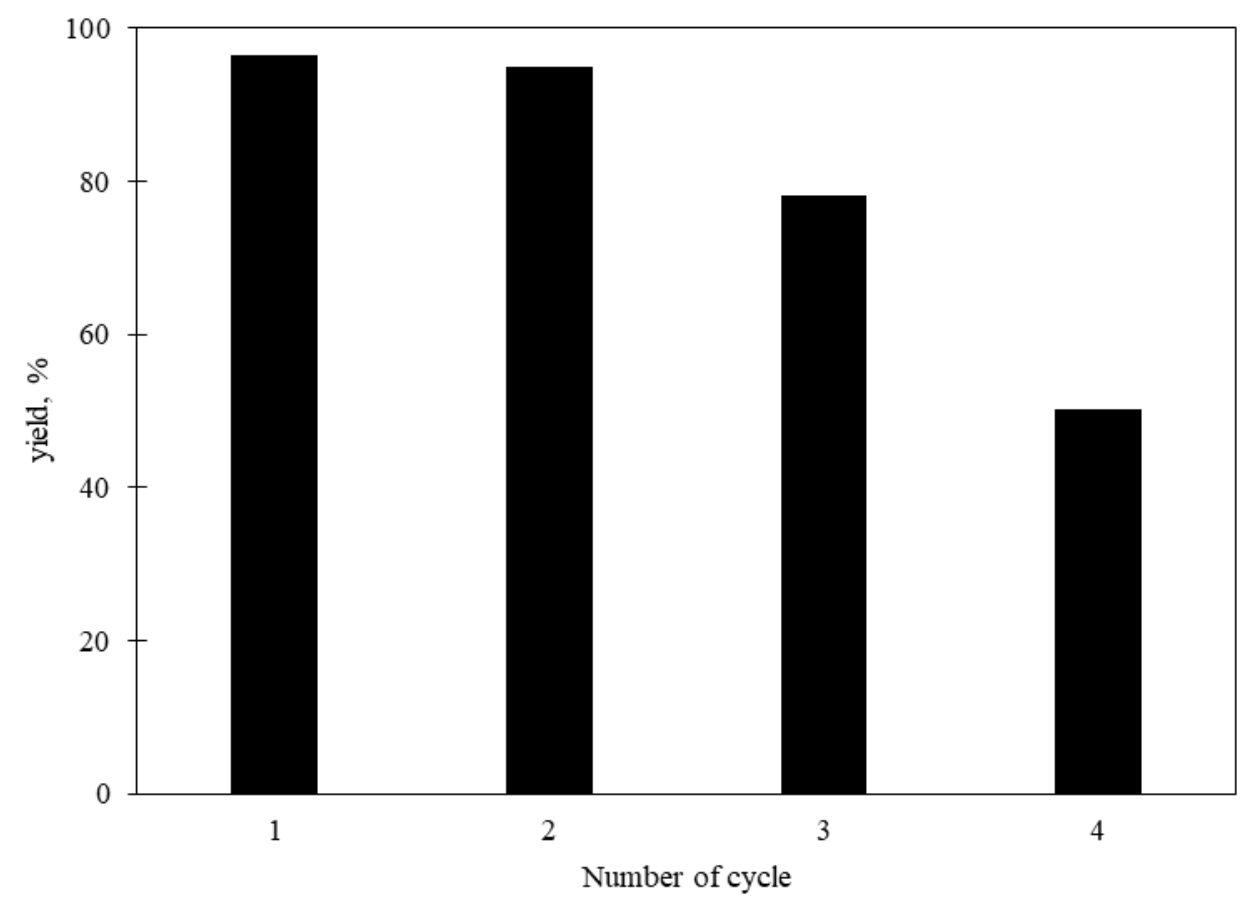

Figure 4. Reaction yield after $60 \mathrm{~min}$ of reaction time in the transesterification of palm oil using freshly-activated catalyst (cycle 1) and $3 \mathrm{x}$-washing (with methanol at $60^{\circ} \mathrm{C}$ )regenerated catalyst (cycle 2,3 , and 4 ).

Using the data at cycle 2 in Figure 3, the kinetics model (described in Materials and Methods section) for the transesterification reaction was developed. Figure 5 shows the calculation results based on the developed kinetics models in comparison to the experimental data. It is seen that the highest degree of fit between calculated and experimental data was obtained from the first order reaction model. This fact suggests that in the presence of methanol excess, transesterification of palm oil is only dependent on the concentration of triglycerides that interact with surface methoxides preliminary formed during (re)activation step of the catalyst with methanol. 


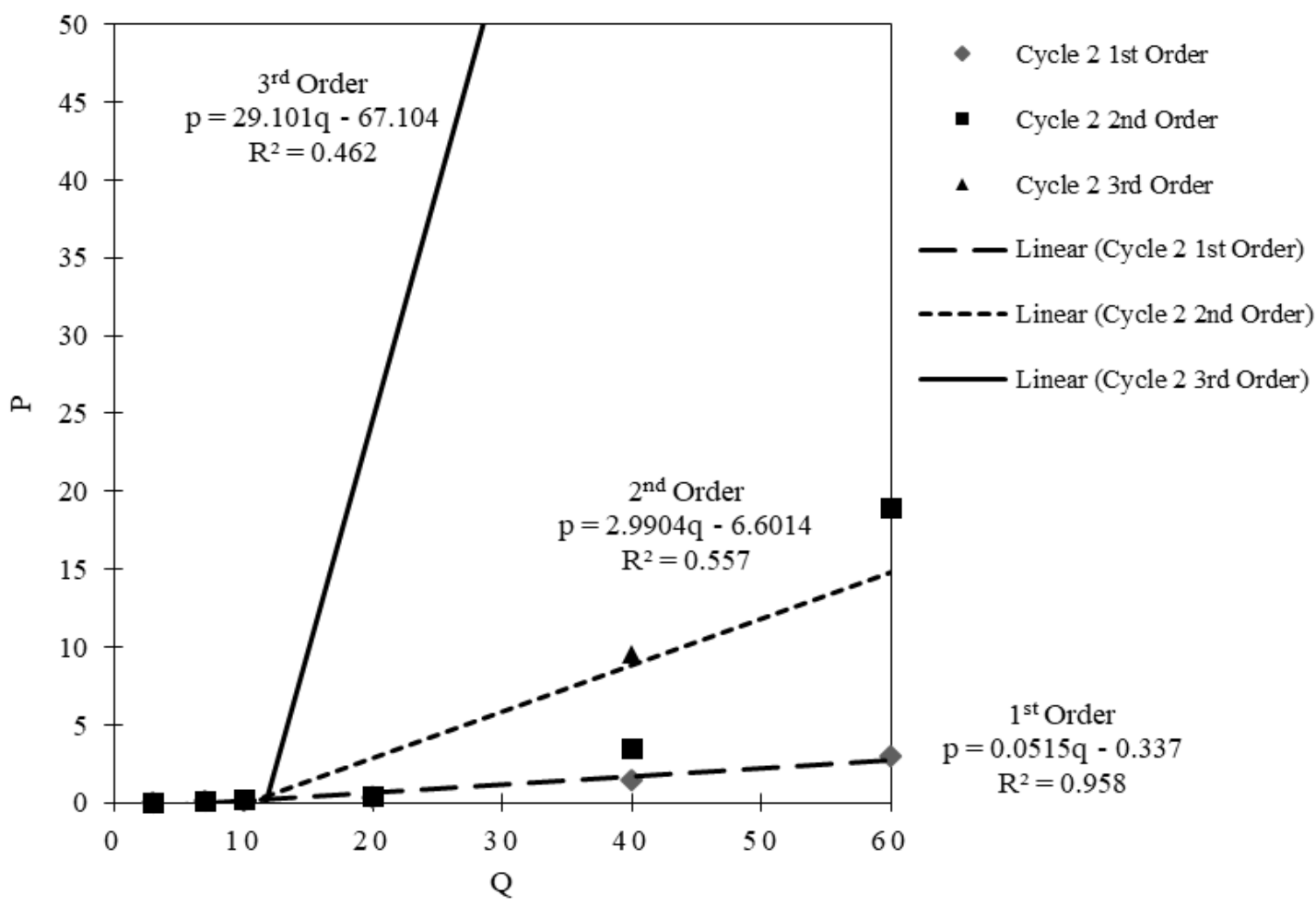

Figure 5. Reaction kinetics model fitted with experimental data.

Using the first order of kinetics as the most suitable model, the activity of sodium silicate catalyst in transesterification of palm oil with methanol in several sequential reaction cycles was evaluated. The catalyst was regenerated using $3 \mathrm{x}$-washing (with methanol at $60^{\circ} \mathrm{C}$ ) method. Linear correlations of the first order kinetics for each cycle are depicted in Figure 6. It is shown that the model can fit all cycles in a relatively good agreement with the experimental data. The rate constant $(\mathrm{k})$ of the transesterification reaction (Equation 1) can thus be determined as the slope of the linier lines and shown in Table 1. 


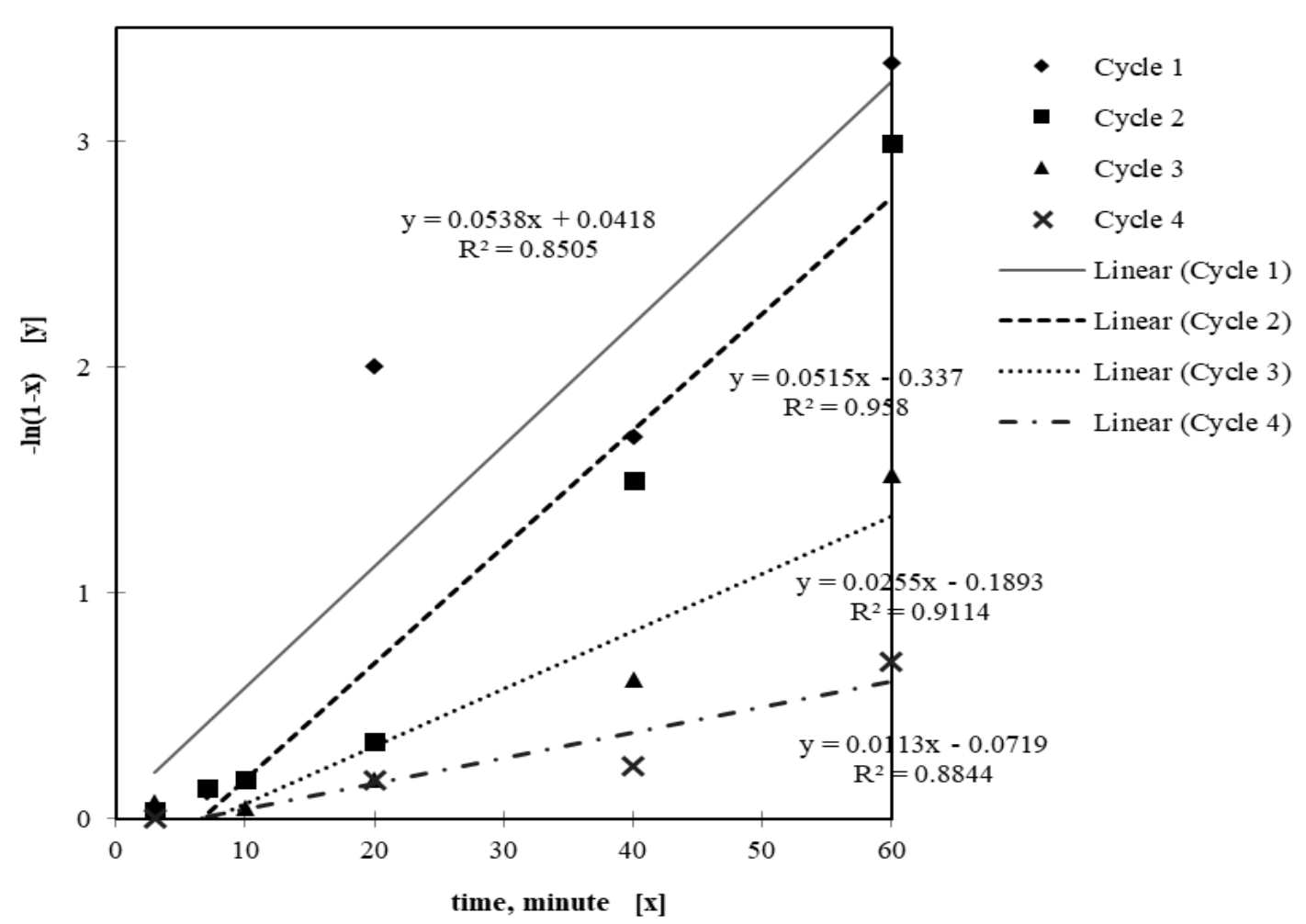

Figure 6. Linear correlation of kinetics model between yield and reaction time for each cycle

Table 6 shows that the reaction rate constants tend to decrease as number of reaction cycle increases. Due to poisoning effect of hydrocarbon compounds on the surface of catalyst, the number of active sites available for the reaction declines. The activity of the catalyst is determined by the availability of the sites where sodium is located in the catalyst. These sodium sites will adsorb methanol molecules during (re)activation steps to form methoxide compounds that later interacts with triglycerides in palm oils. However, the presence of other compounds such as hydrocarbon adsorbed on the sodium sites can hinder the formation of methoxides that eventually inhibit its interaction with triglycerides to form methyl esters.

Table 1. Reaction rate constants at cycle 1,2,3, and 4 in the transesterification of palm oil using $3 \mathrm{x}$-washing (with methanol at $60^{\circ} \mathrm{C}$ )-regenerated catalyst.

\begin{tabular}{cc}
\hline $\begin{array}{c}\text { Number of } \\
\text { cycle }\end{array}$ & $\begin{array}{c}\text { Reaction rate constant } \\
\left(k_{1}\right), \mathrm{min}^{-1}\end{array}$ \\
\hline 1 & 0.0538 \\
2 & 0.0515 \\
3 & 0.0255 \\
4 & 0.0113 \\
\hline
\end{tabular}

In the present work, it is found that even though washing with methanol at elevated temperature can increase the activity of the used catalyst, the activity of the catalyst cannot be completely recovered from deactivation. Even though theoretically sodium silicate is insoluble in methanol, there was an indication that methanol can slightly 
dissolve the sodium from the catalysts. Roschat et al. also reported that some sodium might be leached by reaction mixture [32].

It was indicated that the methanol with sodium silicate catalyst present showed high basicity. However, a decrease of $\mathrm{pH}$ was observed from around 12 to 10 when the catalyst was used in sequence from reaction cycle 1 to 4 . Numbers of washing with methanol during reactivation can also potentially reduce the amount of sodium in the catalyst which actually plays as active sites for the reaction. Further careful study is still required to investigate how the deactivation of the sodium silicate catalysts should be more effectively overcome.

\section{CONCLUSIONS}

The study shows that in principle, catalyst regeneration using both calcination and washing methods can be applied to sodium silicate that is used in transesterification reaction of palm oil with methanol. Both methods, however, result in different degree of catalyst reactivation, in which calcination results in a lower degree of reactivation compared to washing method. Furthermore, the washing method with methanol can be significantly improved by increasing the washing cycle from one to three times, as well as the temperature of the methanol from room temperature to $60^{\circ} \mathrm{C}$. The visually darker and darker catalyst after several calcination process indicated that a larger amount of hydrocarbons were still trapped in the catalyst surfaces and were not burned out during the calcination, leading to catalyst deactivation. The significantly lower transesterification reaction yield observed from the experimental data validates this explanation. Interestingly, washing with methanol instead of calcination as the regeneration process significantly increased the reaction yield that was done after catalyst regeneration. Hypothetically, some fractions of trapped hydrocarbon residues on the catalyst surfaces were replaced by methanol molecules, which is one of the transesterification reactants, leading to enhanced reaction at the next cycle. More hydrocarbons could be replaced by the methanol molecules by repeating the washing step to $3 \mathrm{x}$ and increasing the temperature to $60^{\circ} \mathrm{C}$. The study thus sheds light on the process and parameter selections in sodium silicate catalyst regeneration, in order to prolong its lifetime in the application of transesterification reaction of palm oil with methanol. Moreover, the kinetics study shows that the catalytic transesterification reaction follows the first order reaction, with a reaction rate constant that decreases as the number of reaction cycle increases. This kinetics data should contribute to facilitate scale up design and feasibility study. Further comprehensive investigation, however, is still needed to gain insights on the parameters to further increase the catalyst reactivation degree.

\section{ACKNOWLEDGEMENTS}

This research was funded by PUPT DIKTI 2016 and supported by PT. Geo Dipa Energi and Geothermal Research Centre through UGM-NZ Aid - CaRED Project. 


\section{REFERENCES}

[1] Ahmad R, Hamidin N, Ali UFM, Abidin CZA. Characterization of Bio-Oil From Palm Kernel Shell Pyrolysis. Journal of Mechanical Engineering and Sciences. 2014;7:1134-40.

[2] Gebremariam SN, Marchetti JM. Economics of biodiesel production: Review. Energy Conversion and Management. 2018;168:74-84.

[3] Mohiddin M, Saleh A, Reddy A, Hamdan S. A Study on Chicken Fat as an Alternative Feedstock: Biodiesel Production, Fuel Characterisation, and Diesel Engine Performance Analysis. International Journal of Automotive and Mechanical Engineering. 2018;15:5535-46.

[4] Hasan AH, Avami A. Water and emissions nexus for biodiesel in Iran. Renewable and Sustainable Energy Reviews. 2018;93:354-63.

[5] Abdulrazik A, Noor MZM, Failaka MF, Elkamel M, Elkamel A. Utilising biomass for renewable energy production: optimal profitability evaluation from different processing routes. Journal of Mechanical Engineering and Sciences 2017; 11:3046-57

[6] Tran NN, Tišma M, Budžaki S, McMurchie EJ, Gonzalez OMM, Hessel V, et al. Scale-up and economic analysis of biodiesel production from recycled grease trap waste. Applied Energy. 2018;229:142-50.

[7] Liu X, He H, Wang Y, Zhu S, Piao X. Transesterification of soybean oil to biodiesel using $\mathrm{CaO}$ as a solid base catalyst. Fuel. 2008;87:216-21.

[8] Wang B, Li S, Tian S, Feng R, Meng Y. A new solid base catalyst for the transesterification of rapeseed oil to biodiesel with methanol. Fuel. 2013;104:698703.

[9] Harreh D, Saleh A, Reddy A, Hamdan S, Charyulu K. Production of Karanja Methyl Ester from Crude Karanja Oil Using Meretrix Lyrata Synthesised Active $\mathrm{CaO}$ Catalyst. International Journal of Automotive and Mechanical Engineering. 2018;15:5683-94.

[10] Liu X, Piao X, Wang Y, Zhu S, He H. Calcium methoxide as a solid base catalyst for the transesterification of soybean oil to biodiesel with methanol. Fuel. 2008;87:1076-82.

[11] Guo F, Peng Z-G, Dai J-Y, Xiu Z-L. Calcined sodium silicate as solid base catalyst for biodiesel production. Fuel Processing Technology. 2010;91:322-8.

[12] Long Y-D, Guo F, Fang Z, Tian X-F, Jiang L-Q, Zhang F. Production of biodiesel and lactic acid from rapeseed oil using sodium silicate as catalyst. Bioresource Technology. 2011;102:6884-6.

[13] Perdana I, Nugrahanti N, Sofiyah, Bendiyasa IM. Transesterification of palm oil using sodium silicate base catalyst from geothermal sludge. IOP Conference Series: Materials Science and Engineering. 2016;162:012024.

[14] Cha MS, Park KY. Preparation of Sodium Silicate from Clay. Journal of Chemical Engineering of Japan. 2001;34:232-5.

[15] Kaduku T, Daramola MO, Obazu FO, Iyuke SE. Synthesis of sodium silicate from South African coal fly ash and its use as an extender in oil well cement applications \% J Journal of the Southern African Institute of Mining and Metallurgy. 2015;115:1175-82.

[16] Mroczek E, Graham D, Siega C, Bacon L. Silica scaling in cooled silica saturated geothermal water: Comparison between Wairakei and Ohaaki geothermal fields, New Zealand. Geothermics. 2017;69:145-52. 
[17] Muljani S, Setyawan H, Wibawa G, Altway A. A facile method for the production of high-surface-area mesoporous silica gels from geothermal sludge. Advanced Powder Technology. 2014;25:1593-9.

[18] von Hirtz P. 16 - Silica scale control in geothermal plants - historical perspective and current technology1. In: DiPippo R, editor. Geothermal Power Generation: Woodhead Publishing; 2016. p. 443-76.

[19] van den Heuvel DB, Gunnlaugsson E, Gunnarsson I, Stawski TM, Peacock CL, Benning LG. Understanding amorphous silica scaling under well-constrained conditions inside geothermal pipelines. Geothermics. 2018;76:231-41.

[20] Sádaba I, López Granados M, Riisager A, Taarning E. Deactivation of solid catalysts in liquid media: the case of leaching of active sites in biomass conversion reactions. Green Chemistry. 2015;17:4133-45.

[21] Zhu W, Zhang J, Kapteijn F, Makkee M, Moulijn JA. Hydrodechlorination of 1,2dichloropropane over $\mathrm{Pt}-\mathrm{Cu} / \mathrm{C}$ catalysts: Coke formation determined by a novel technique-TEOM. In: Spivey JJ, Roberts GW, Davis BH, editors. Studies in Surface Science and Catalysis: Elsevier; 2001. p. 21-8.

[22] Guisnet M, Ribeiro FR. Deactivation and Regeneration of Solid Catalyst. Deactivation and Regeneration of Zeolite Catalysts: Imperial College Press; 2011. p. 3-18.

[23] Dermawan MR, Gemilar GP, Perdana I, Bendiyasa IM. Deactivation of Sodium Silicate Base Catalyst in Transesterification of Corn Oil with Methanol. 27th Symposium of Malaysian Chemical Engineers (SOMChE 2014) in conjunction with the 21st Regional Symposium on Chemical Engineering (RSCE 2014). Taylor's University Lakeside Campus, Selangor Darul Ehsan, Malaysia: Taylor's University; 2014.

[24] Du J, Gao J, Gu F, Zhuang J, Lu B, Jia L, et al. A strategy to regenerate coked and sintered Ni/Al2O3 catalyst for methanation reaction. International Journal of Hydrogen Energy. 2018.

[25] Kosinov N, Coumans FJAG, Li G, Uslamin E, Mezari B, Wijpkema ASG, et al. Stable Mo/HZSM-5 methane dehydroaromatization catalysts optimized for hightemperature calcination-regeneration. Journal of Catalysis. 2017;346:125-33.

[26] Esmaeili J, Rahimpour F. Regeneration of spent nickel catalyst from hydrogenation process of edible oils: Heat treatment with hydrogen injection. International Journal of Hydrogen Energy. 2017;42:24197-204.

[27] Yao Y, Huang W. An Effective Regeneration Method for $\mathrm{CaO} / \mathrm{MgO}$ Catalyst Used in Biodiesel Synthesis. Energy Sources, Part A: Recovery, Utilization, and Environmental Effects. 2011;34:261-6.

[28] Christou SY, Birgersson H, Fierro JLG, Efstathiou AM. Reactivation of an Aged Commercial Three-Way Catalyst by Oxalic and Citric Acid Washing. Environmental Science \& Technology. 2006;40:2030-6.

[29] Gonzalo A, García M, Luis Sánchez J, Arauzo J, Peña JÁ. Water Cleaning of Biodiesel. Effect of Catalyst Concentration, Water Amount, and Washing Temperature on Biodiesel Obtained from Rapeseed Oil and Used Oil. Industrial \& Engineering Chemistry Research. 2010;49:4436-43.

[30] Yu Y, He C, Chen J, Yin L, Qiu T, Meng X. Regeneration of deactivated commercial SCR catalyst by alkali washing. Catalysis Communications. 2013;39:78-81.

[31] Mahlaba SVL, Valand J, Mahomed AS, Friedrich HB. A study on the deactivation and reactivation of a Ni/Al2O3 aldehyde hydrogenation catalyst: Effects of 
regeneration on the activity and properties of the catalyst. Applied Catalysis B: Environmental. 2018;224:295-304.

[32] Roschat W, Siritanon T, Yoosuk B, Promarak V. Rice husk-derived sodium silicate as a highly efficient and low-cost basic heterogeneous catalyst for biodiesel production. Energy Conversion and Management. 2016;119:453-62.

[33] Deshmane VG, Adewuyi YG. Synthesis and kinetics of biodiesel formation via calcium methoxide base catalyzed transesterification reaction in the absence and presence of ultrasound. Fuel. 2013;107:474-82.

[34] Gui X, Chen S, Yun Z. Continuous production of biodiesel from cottonseed oil and methanol using a column reactor packed with calcined sodium silicate base catalyst. Chinese Journal of Chemical Engineering. 2016;24:499-505. 